\title{
History of Medicine and Medical Law
}

\section{Mukhitdinova Firyuza Abdurashidovna}

Doctor of Law, Professor of Tashkent State University of Law, Uzbekistan

Abstract
The article discusses the history of the development of traditional medicine and the human right to treatment. The ancestors of folk
medicine and the legal regulations in this area are studied. The state of medical activity and medical law of Uzbekistan is analyzed.

Corresponding author: Mukhitdinova Firyuza Abdurashidovna, Doctor of Law, Professor of Tashkent State University of Law, Uzbekistan. E-mail: feruza.mukhitdinova@gmail.com

Keywords: Traditional Medicine, Doctor, Scientists, Sources, Law, Law Management

Received: November: 10, 2019, Accepted: November: 19, 2019, Published: November 29, 2019

\section{Introduction}

As we know, the World Health Organization (WHO) as early as 1948 formulated that "health is a state of complete physical, spiritual and social well-being, and not just the absence of diseases and physical defects." WHO has proclaimed the principle that "the enjoyment of the highest attainable standard of health is one of the fundamental rights of every person". At the beginning of the Middle Ages, the main agricultural population of Central Asia was the ancestors of the peoples now inhabiting the Central Asian republics: Uzbeks, Turkmens, Kara-Kalpaks (Khorezmians and Turkic-speaking tribes and peoples living in the regions of Tashkent and Bukhara), Tajiks (Bactrians, Sogdnians and relatives and nationalities). The culture of these peoples was distinguished by a high level. Long before the beginning of our era, the farmers of Central Asia learned to draw channels for irrigation of fields and created flowering fertile oases. The ancestors of the peoples of Central Asia built large cities with large buildings, surrounded the city with strong walls, and built dams. Various crafts were developed in the cities.

The Purpose and Objectives of the Study The main objective of the study is the study of relics of ancient medicine, folk treatment in religious beliefs in the traditional way of life of the peoples of Uzbekistan. Based on this goal, the article sets the following tasks: - Describe the history of the emergence of ancient folk healing and and characterize their essence; - Introduce new materials reflecting local features of traditional medicine, traditions and rituals practiced among Uzbeks to the present - Determine the degree of development of traditional medicine, reveal the mechanism of interaction of Islam with traditional medicine - Identify the place and importance of traditional medicine in the system of the spiritual worldview of the people 
. Consider the genesis and evolution of individual customs, rites and traditions that are part of this cycle.

- Research Methods. The principle of historicism generally accepted in historical and ethnological studies, comparative and complex analysis.

\section{Discussion}

Central Asia over the 9th century has grown economically so that in the 10th century it was the most advanced region of the Middle East, at least economically, politically and culturally more progressive than the regions of Iran. The Samanid state had favorable conditions for the development of agriculture, crafts and trade. Ancient trade routes connected the Samanids with China, India, Russia, the countries of the Caucasus and the Mediterranean. The dominance of religion, characteristic of feudalism, came to Central Asia later - from the end of the XI century. Before that, the relative freedom of scientific consciousness, creative scientific thought in philosophy and natural science is still visible. Under the Samanids and subsequent dynasties in the $\mathrm{X}$ and $\mathrm{XI}$ centuries, the culture of the peoples of Central Asia reached a high development. By the 9th - 10th centuries, a number of economic, political, and cultural centers had developed in Central Asia. Central Asia was not only one of the most fertile and wealthy, but also one of the most cultivated lands of the East. The capital of the Samanid state of Bukhara and the capital of Khorezm Urgench were centers of science and art: in Bukhara there was a library of Samanids, in Khorezm there was a society of scientists (academy). In large cities, there were hospitals and pharmacies.

The peoples of Central Asia during the early Middle Ages were nominated by many scientists (historians, mathematicians, geographers, botanists, astronomers) and art, whose work was an important contribution to the development of world culture.

Among scholars of Central Asia of that time, rooks occupied a prominent place, which played a large role in the development of medicine. In the countries of the East, in particular in Central Asia, in the 9th-11th centuries there were numerous hospitals. Experienced doctors worked in Bukhara, Khorezm, Merv and other cities of Central Asia in those years.

Medicine was a natural manifestation of the high culture of the peoples of Central Asia. The most prominent representative of Central Asian doctors was Abu Ali Ibn Sina (known in Europe under the name Avicenna), the largest doctor of the Middle Ages and one of the most prominent doctors in world history. He was born in 980 in the village of Afshan near the city of Bukhara. At the age of five, his parents moved him to Bukhara, where his studies began. From teachers and from the books of the rich Bukhara library of Samanids, Ibn Sina received all the knowledge known at that time. However, Ibn Sina studied medicine more deeply and thoroughly. In his autobiography dictated to him, he said: "I began to study medicine, replenishing the reading with the observations of patients, which taught me many treatment methods that cannot be found in books."

The medical activity of Ibn Sina, which had begun successfully in Bukhara, was interrupted. The Samanid dynasty that ruled in Bukhara was overthrown, and Ibn Sina was forced to leave for Khorezm, where he met with the famous scientist of that time Biruni, with the outstanding doctor Abul-Hassan-Hammar, etc.

Stay in Khorezm coincided with the flowering of creative scientific activity of Ibn Sina. But Khorezm was threatened by the fierce conqueror Sultan Mahmud Ghaznevi, Ibn Sina fled from Khorezm and spent all subsequent years in wanderings in different cities of the Caspian region and Iran. For a swap of views, Ibn Sina was repeatedly harassed and imprisoned. But everywhere Ibn Sina continued his scientific and medical activities. In 1037, at the age of 57, Ibn Sina died in Hamadan (Iran), where his grave is still preserved. Ibn Sina left numerous works on various branches of knowledge: philosophy, mathematics, physics, astronomy, chemistry, etc.

A characteristic feature of the spiritual appearance of Ibn Sina was the independence of thought. Ibn Sina ridiculed astrologers, rejected the dogmas of the 
Muslim religion. Contrary to the Qur'an, Ibn Sina claimed that the world was not created, but eternal. Ibn Sina fought against the doctrine of predestination, of fate, of fate, which denied the freedom of human will, belittled the role of the human person. Long before the advanced philosophical thought of Europe put observations and experiments in the first place, Ibn Sina applied observation and experience in solving medical problems. Ibn Sina's writings everywhere show a love of scientific knowledge, verification by observation and experience, and faith in the human mind.

Ibn Sina's observations of natural phenomena led him to important discoveries and conjectures in the field of natural sciences, which were ahead of other scientists by centuries. The historians of chemistry and geology call the name of Ibn Sina among the honorary number of people who laid the foundations for these sciences. For several centuries, future doctors studied medicine in Western European universities according to the "Canon of Medicine" and the work of Ibn Sina thus shaped the medical thinking of many generations. The first paragraphs of the "Canon of Medical Science" are remarkable, where Ibn Sina gave a definition of medicine and its tasks: "I affirm: medicine is a science that knows the state of the human body, because it is healthy or will lose health in order to maintain health and return it if it is lost."

The Canon of Medical Science is divided into five books. The first book contains a definition of the concept of medicine, information on anatomy and general information about diseases, their causes and manifestations, about maintaining health and methods of treatment in general. The second book outlines the doctrine of simple medicines and their methods of action. The third book contains private pathology and therapy, a description of individual diseases and methods for their treatment. The fourth book is about surgery and the general doctrine of fever. The fifth book describes complex medicinal substances, poisons and antidotes. Ibn Sina paid much attention to the issues of health protection and disease prevention, since the nature of the disease at that time remained unknown, often there were no effective methods of treatment. Ibn Sina very briefly stated the laws of health and in a clear system listed the external and internal forces that influence his preserva- tion. Highly appreciating the feasibility of most of the hygienic statements of Ibn Sina, it should be emphasized at the same time that there was a big gap between them and life. If the dominant exploiting elite of feudal society could use the instructions of Ibn Sina, then the general public, oppressed and plundered, often under double oppression - their rulers and foreign invaders, entangled in religious prejudices, living in poverty, in most cases could not dream of -1 the implementation of the hygiene rules that Ibn Sina insisted on. In the Middle Ages, the state of Khorezmshahs reappeared on the world stage. The former glory of ancient Khorezm was restored. Shah Mamun Ibn Muhammad unified the northern and southern Khorezm kingdoms and created a unified Khorezm state. Its capital is Urgench.

Culture and science achieved particular prosperity during the reign of Mamun Ibn Mamun. Many scientists, philosophers, hakims, musicians and singers lived and worked in his palace. Scientists who lived in the palace of Khorezmshah were united in the "Majlisi Ulamo" ("Meeting of Scientists") known in history under the name "Mamun Academy." The Academy was led by the great scientist Abu Raikhan Beruniy. The "Academy" consisted of specialist scientists in all then well-known branches of science. Including experienced hakims. In the list of its members we found the names of the doctors Abu Ali Ibn Sina, Abu Sahla Masihiy, Sharafuddin Ibn Abdullo Ilokiy, Abu Mansur Kamariy and Abu Khaira Hammara. The Mamun Academy played an important role in the development of various sciences, including medicine. In Urgench and other cities, hospitals, hospitals, pharmacies and other institutions were built, in which experienced tabibi and pharmacists worked.

For example, Abu Sahl Masihiy was an experienced tabib, a doctor. He is from Jurjan. Abu Sahl Masihiy was a Christian. He studied in Baghdad, and received a medical education there. Then, having returned to Dzhurzhan, he began to practice medicine. After some time, he moved to Urgench, where he was admitted to the Mamun Academy. In addition to medicine, Abu Sahl Masihiy was engaged in philosophy, logic and other sciences. But he was more famous as a connoisseur of theoretical medicine. In the books. Abu Sahl Masihiy on medicine "One hundred problems of medicine", "Book on general medicine", "Treatise on smallpox", 
Citation: Abdurashidovna MF (2019) History of Medicine and Medical Law Journal of Media \& Management. SRC/JMM-101. DOI: doi.org/10.47363/JMM/2019(1)101

"Book on cholera", "Fundamentals of medicine", etc. Also famous is Abu Abdullah Ilokiy who was one of the famous tabibs, a folk doctor of that time.

Abu Sahl Masihiy was born in the town of Ilok near Tashkent in the area of modern Akhangaran. His birth year is unknown, he died in 1068. Ilocius originally studied in Shosh. For a deeper study of medicine, he went to Bukhara, and then to Urgench, where he really gained good knowledge in medicine and other sciences. In Bukhara and Urgench, he improved his experience in the field of medicine in practice and soon became a major scientist and tabib.

We know the following works of Ilokii on medicine: "On the causes and signs of diseases", "Methods of treatment", "Collection of medicine", "Extract from the collection of medicine", "The abridged canon".

In the book "On the Causes and Symptoms of Diseases", based on a study of literary sources and his experience, the scientist highlights the causes and occurrence of various diseases. When diagnosing, Ilokiy recommends paying attention to the manifestation of the disease, the nature of the pulse. He emphasizes the importance of studying the secretions of the body - sputum, feces and urine, especially paying attention to the color, transparency, texture and smell of the latter. The book "Methods of treatment" outlines all the then known methods of treating diseases. Therapeutic, surgical, diet therapy, bloodletting. Paying special attention to diet therapy, the scientist indicates that sometimes the patient can be cured by prescribing only the appropriate diet.

The "Collection of Medicine" analyzes all the basic data on theoretical and practical medicine of its time. The book summarizes the experience of doctors living in Ilokiy and contemporaries. The "Abridged Canon" is an abridged version of the "Canon of Medicine" by Abu Ali ibn Sina. Abu Khayr ibn Hammar was also one of the famous Tabibs. He was born in 942 in Baghdad, where he received his education and medical specialty. For a long time, Abu Khayr ibn Hammar worked as a doctor in this city. Then, already in adulthood, he was invited to Khorezm, where he served as a court doctor with the Khorezm shah Mamun ibn Muhammad. At the request of Mahmud Ghaznevi, the scientists of Khorezm went to Ghazna, among them was Abu Khayr ibn Hammar.

Abu Khayr ibn Hammar owns several treatises on med- icine. The main ones are "The Test of Doctors", "The Structure of Human Organs", "Treatise on the Substantial Disease", "On the Nutrition of the Elderly" and others.

In XII the Khorezm state became the most powerful in Central Asia. Science, literature and art flourished. The famous scientist and doctor of that time Ismail Dzhurzhoniy wrote that the Khorezm shah Kutbiddin $\mathrm{Mu}$ hammad suffers only from a disease.

During the reign of Kutbiddin Muhammad, the Academy resumes its activity, to which scientists from different countries and cities are invited. The "Academy" often hosts conversations, tips and debates. By this time, medicine has been developing significantly. Large medical scientists appear. Of the large doctors who lived then in the Khorezm state, we know Ismoil Dzhurzhoniy, Umar Chagminiy etc [1].

Medicine has always occupied a special place in the East. Healers of Central Asia possessed such knowledge in the field of treatment and health promotion, which in our days have not lost their applied value. As we know, traditional medicine has always served the people, therefore, Islamic law supported alternative treatment, if only specialists in their field were involved in it. In the Muslim criminal or, rather, tort, law, depending on the nature of the punishments provided for the crime, three types of offenses are distinguished.

The first group consists of crimes representing the greatest public danger: hadd (Arabic. "Restriction"), or hoodood (plural of the word hadd). There are direct references to them in the Qur'an and the Sunnah or in their respect the unanimous opinion of the companions of the prophet is formulated. Among Muslim jurists, there is no agreement on what crimes can be classified as hadd. If you take the most complete list, then such theft includes qualified theft (sarika), adultery, false accusation of adultery, drinking, robbery, rebellion, betrayal of Islam [2].

The second group is crimes, the sanction for the commission of which is based on the principle of the talion: kisas (Arabic: "retribution to equal"). These include, first and foremost, murder and bodily harm of an irreversible nature.

The third group of offenses is ta'zir (Arabic: "retention"): in the modern criminal codes of some Muslim countries, this group includes all offenses - with the 
exception of those belonging to the categories of hadd and kisas. So if a patient dies through the fault of a medicine, then this crime belongs to the second category - kisas. So he committed a deliberate murder. In favor of the presence of intent, says, among other things, lack of knowledge of healing and the essence of the crime. Therefore, we can say that treatment of a person is always connected with a human right, because it is not in vain that medical law is said.

In the future, even under Amir Temur and Temurids, special attention was paid to the development of medical knowledge, the construction of hospitals. According to sources, the Tabibs worked at those who studied at madrassas and other educational institutions [3].

In Herat, there was a hospital Dar al-Shifa, built during the reign of Amir Temur, the wife of his son Umarsheikh Mahdiulya Milkat aga. This beautiful building, erected with exceptional craftsmanship, was located on the south side of Masjidi Jame, located outside of Herat. A house was dug between the hospital and the Dar al-Huffaz building, located on the north side of the mosque, which was used by the hakims and tabib doctors to heal the sick. In addition, there was the Gift of Al-Shifa, built in Bagi Zagan in Herat.

Alisher Navoi built many socially useful buildings in Herat, including Dar Al-Shifa and Shifaya Hospital in Incil. Public hospitals also included pharmacies where pharmacists worked (daripaz), preparing various medicines for patients. Herat Tabibs were especially famous for the treatment of ocular, vascular and gastrointestinal diseases [4].

Many educated doctors of that time simultaneously treated patients in these hospitals and taught at educational institutions. According to Sharafad Din Ali Yazdi and Ibn Arabshah, Amir Temur brought from Sham (Syria) to Samarkand the head of the Tabibs Mawlan Jamapaddin and Mawl to Suleiman. His personal doctor was a tabib named Mawlana Fazlallah Tabrizi. In addition, such well-known doctors as Mawlana Izzaddin Masoud Shirazi and Mawlana Farrukh tabib served at the court of Sahibkiran.

The well-known physician Mansur ibn Muhammad ibn Ahmad ibn Yusuf ibn Fakih Ilyas wrote several medical compositions, among them "Risa la don tashrihi badani insan" (A treatise on human anatomy), also known as "Tashrihi Mansuri", dedicated to the grandson of Amir Temur - Pir Muhammad Bahadir. His second work "Kifayi Mansuri" is named after the author's teacher Maja Haddin.

At the court of Shahrukh, the most prominent scientists and doctors of that time were very popular: Mawlana Shamsaddin Muhammad Adam and Mawlana Nizamaddin Shirazi tabib. Burhanaddin Nafis ibn Ivaz ibn Hakim alKermani, a native of a family of doctors in Kerman, arrived in Samarkand at the invitation of Ulugbek and became his personal physician.

In 1424, he wrote a commentary in Arabic on the medical work Al-asbab val-alamat (Causes and Signs of Diseases) of Najibaddin Samarkand devoted to diseases "from head to toe" and presented it to Ulugbek. In his work, he included some excerpts from the commented composition, thanks to which the work of Najibaddin Samarkandi became known to science. In 1438, he also compiled Sharh al-Mujaz (Commentary on the abbreviation of the Canon), a commentary on the work of another famous physician, Allauddin Ali Abulharam al-Qarshi, known as Ibn al-Nafis. Among the court physicians of Sultan Hussein Baykara was the famous scientist and doctor Mawlana Muhammad. The healers enjoyed the patronage of Alisher Navoi and treated the sick while teaching at Dar al-Shifa.

Mawlana Giyasaddin Muhammad ibn Mawlana Jalaladdin tabib was deeply competent in many branches of science. He especially proved himself in the field of medicine by writing a well-known short and accessible form commentary on the work "Mualjat Ilaki" (Methods of treatment of Ilaka). He also compiled "Hashiyayi Sharh Mujaz" Mawlana Nafisa (Commentary on "Sharh Mujaz"). In this case, it refers to the work of the aforementioned Burhanad Din Nafisa ibn Iwaza al-Kermani.

For several years, Mawlana Kamaladdin Masoud Shirvani taught at the Gavharshadag Madrasah and the Ihlasiya Madrasah with the support of Shahrukh. He possessed special talents not only in medicine, but also in the science of words and logic. Later he taught at the Giyasiya madrasah. He had a good command of the bloodletting method, which was widely used then. His pen belongs to two medical compositions that were popular among students of madrassas, as well as excel- 
During the reign of the Sheybanids in Mavarennahr (Uzbekistan), medicine was significantly developed. Then in almost every city there were hospitals, pharmacies, madrassas with a medical bias, and other sanitary facilities. For example, in the middle of the sixteenth century. in Tashkent, in the picturesque place of Chorbag, the Shifo-Khona hospital (hospital) was built, in which sick and wounded soldiers were treated. Wellknown tabibs worked in hospitals, and experienced scientists taught in medical schools. By this time, medicine was significantly differentiated, and tabibs-specialists in separate sections of practical medicine began to appear. Shah Ali ibn Sulayman al-Kahhal was from Tashkent. Here he studied and received his education. Having become a tabib, he began to treat patients, mainly with eye diseases. According to his specialty, he wrote a work entitled "Zubda and Manzuma, the Gift of Fani Kakhholii" ("A Poem on Eye Diseases"). Shah Ali Sulayman was a good poet. Therefore, he wrote his work in a poetic style. The book outlines the structure, physiology and pathology of the eye. The methods of treatment of various eye diseases are indicated. Prescriptions are given for the manufacture of medicines for treating the eyes.

Ali al-kahhal was one of the prominent Tabiban scholars of the time. Officially, he was considered an eye doctor (kahhal). But, apparently, Ubaidullo ibn Yusuf was involved in the treatment of other diseases. So, in his work, "Shifo ul-alil" ("Healing the sick"), diseases of almost all organs of the human body are described. The work consists of two books. The first describes the various organs of their diseases and treatment. In the second book, the author gives information about complex medicinal substances, their composition and methods of use. The book "Healing the sick" by Ubaidullah ibn Yusuf played an important role in the history of medicine in Central Asia. By the end of the sixteenth century, the state of schaybonids weakened as a result of feudal strife. The ruler of Movarounnahr was elected Koki Muhammad - a representative of another kind of Uzbek tribes - Ashtarkhanids. In the political, economic and cultural life of the country at this time there were no significant changes. By virtue of necessity, small hospitals were built, and sometimes special madrassas, in which students were trained. For example, in 1682 in
Bukhara the hospital "House of Healing" was built. Its construction is connected with the name of the ruler of Bukhara Subkhankulikhan Subkhankulikhan took care of preserving the health of the population, so that in the summertime bakers baked sesame bread throughout his territory. This was explained as follows: in the summer, due to the onset of heat, gastrointestinal disorders increase among the population, and sesame has a fixing effect. Subkhankulikhan also has medical works. The main work "Subhanovo revitalization of medicine." It consists of an introduction and eight independent chapters. Each chapter in turn is divided into 4 sections. The book outlines the diagnosis and treatment of diseases of individual organs of the human body. This book, according to the famous orientalist and traveler G. Vamberi, was translated into German and distributed in Europe. In the introduction, the author indicates that when writing this work, in addition to the works of other tabibs, he used his personal experience in the diagnosis and treatment of various diseases. Dzhunaidullo Khozyk was one of the famous scientists and tabibs of the late XVIII and early XIX centuries. He was born and received a good education in Herat, he knew history, poetry and medicine. At the beginning of the XIX century. Moved to Bukhara, where he was engaged in medical activities. Thanks to deep knowledge and wide practical experience, Dzhunaidullo Khozik well diagnosed and successfully treated patients, won great authority and respect. In addition, he was engaged in literary activity, wrote poetry and historical works. Known for his commentary on the book of Umar Chagminius "The Small Canon". He called his translation "Verification and Revealing of Truth." She presents a peculiar analysis of the "Small Canon". In it, Hozik identifies the positive aspects and indicates its shortcomings. Khozik played an important role in the history of medicine in Uzbekistan at the end of the 18th and first half of the 19th century. Jafar Khozaraspiy life and activity (late 18th and early 19th centuries) was one of the last Khorezm medical scientists. He had sufficient theoretical knowledge and extensive practical experience. His views were based on the prevailing doctrine of misage and humoral theory in eastern medicine. Based on this, before giving 
the patient a medicine, he recommends a cleansing procedure - bloodletting. He emphasized that his actions depend on the intended outcome of the disease. Known for his work "Collection of medical knowledge." In content, it resembles the third book of the Canon of Ibn Sina Medical Science. It describes the diseases of individual organs, there is information about helminthiases (rishte), skin diseases (warts, vitiligo, furunculosis), poisons and antidotes, some infectious diseases (smallpox, chickenpox, rubella, whooping cough, etc.). In addition, methods for the manufacture and use of drugs are provided.

In the development of medical science in the republic, societies of doctors were important. The first society of doctors and natural scientists in Turkestan was formed in 1870 in Tashkent. Its organizer and first scientific secretary was the famous natural scientist A.P. Fedchenko. In 1892, doctors then working in Turkestan formed the Ferghana Society of Physicians. Then medical societies were created in other cities, as well as societies of doctors in certain specialties - therapy, surgery, ophthalmology, dermatology and venereology, hygiene, etc. In 1957, a society of medical historians of Uzbekistan was organized. In the development of medical science and practical health care an important role was played by congresses and symposia held in the cities of Uzbekistan. The first scientific congress of doctors of Turkestan was held on October 23-28, 1922 in Tashkent. It was attended by 188 delegate doctors from different cities of Turkestan (Central Asia).

At the congress 82 scientific reports on various issues of medical science and practice were heard. On February 5-8, 1927, the First Congress of Doctors of Uzbekistan was held in Samarkand. This was the first congress of doctors to create Uzbekistan. It considered important topical scientific and organizational problems facing the health care system of the republic. The most important tasks solved on the territory of Uzbekistan in the 20th century were the creation of not only a scientific, but also educational base for training medical personnel, improving the health status of the population, strengthening the material and technical base of health care, improving the system of training and retraining of medical personnel, continued reforms in the health system, the introduction of new forms and methods of organizing medical care for the population.
In the 50s-60s. Last century, the public health service was considered as an advanced national system of medical care organization. However, a number of significant systemic defects of this system were subsequently identified:

- Deficit of financial and other health resources due to the unstable state of budgets during periods of economic downturn and the inefficient distribution of material and special resources

- Limited material incentives in the activities of medical workers and institutions

- General low salary level for doctors

- Weak dependence of the remuneration of medical workers and financing of medical institutions on the volume and quality of work performed

- The inability to choose a doctor and medical facility by the patient

- Weak introduction of new methods of diagnosis, treatment and prevention of diseases;

- The diversion of significant financial resources to the maintenance of institutions

- Poor facilities of institutions

- The private healthcare system is based on voluntary (private) medical insurance and direct payment of medical care by consumers (paid medicine)

- Features of a private system:

Predominantly non-state, commercial status of insurance, medical and other organizations accumulating health care funds and providing medical care

- Free (unregulated) pricing of medical services

- High proportion of national income allocated to health

- The main source of financing for medical care is personal funds of citizens and profit (income) of legal entities

- A wide range of medical institutions, varying in the level of quality and cost of medical services, ensuring the satisfaction of various individual needs

- Special attention to the quality of medical care, consumer protection

High incomes of doctors and other medical workers. The task set by the President of the country in the first year of independence - to achieve the level of equipping medical institutions of the best clinics in the West - required highly qualified specialists. A huge step 
Citation: Abdurashidovna MF (2019) History of Medicine and Medical Law Journal of Media \& Management.

was taken in the retraining of personnel. Having identified this direction as the key one, the Ministry of Health of Uzbekistan raised internship issues in a circle of fundamental issues so that ordinary doctors could adopt everything of value that their foreign colleagues own. Indeed, the final result of the reforms mainly depends on the skill of the medical staff. Gained experience, mastered advanced technologies in leading clinics, academies of Israel, USA, Japan, Europe sent to study from all regions of the republic. In those days, UNESCO published the following data: the overall mortality rate in Uzbekistan with an indicator of 5.3 per thousand people is two times less than in most countries of Eastern Europe, three times less than on the entire European continent. Behind the recognition of the authoritative international organization of the achievements of an independent republic in the social sphere was truly titanic work, which resulted in the opening by then, for example, of the last stage of the Scientific Center of Urology. Here, up to 6 thousand patients could receive highly qualified care annually.

Thanks to a thorough examination, he is given an accurate diagnosis, effective treatment is carried out, and scientific research allows to reveal the etiology and pathogenesis of serious diseases. It is also the launch of a new high-energy building at the Center for Oncology and Radiology, where specialists, without destroying healthy cells, just struck a malignant tumor, having at their disposal the most powerful installations in the world. This is the creation in the areas of neonatal clinics, screening centers, computer laboratories capable of analyzing almost a thousand biological samples per day, identifying 60 types of hereditary metabolic diseases that were not previously diagnosed in the republic. The Republican Perinatal Center, in terms of its functions and equipment with progressive equipment, has no analogues throughout the CIS. Since the mid-1980s in our country, continuous reform of health care was carried out, first in the form of the so-called new economic mechanism (from 1987 to 1991), and from 1992 to the present, in the form of the establishment of a health system based on social insurance.

Today, in Uzbekistan, as part of the implementation of measures to reform the healthcare system in the republic, it was possible to achieve certain results in the formation of a modern system for providing medical assistance to the population adopted the Concept of development of the health system of the Republic of Uzbekistan for 2019-2025 and a program of measures to implement the Concept of development of the health system of the Republic of Uzbekistan in 2019-2021, which indicate that, over the past period, the system of primary health care has been improved through the organization of rural doctors points, urban and rural family clinics, increased its accessibility to the population. A unified centralized system of emergency medical care has been created, a network of republican specialized scientific and practical medical centers providing hightech medical services to citizens has been improved, including in the field.

A number of targeted national programs have been implemented to strengthen the reproductive health of the population and protect the health of mothers and children. Republican and regional screening centers have been organized to ensure the prevention of the birth of children with hereditary and congenital diseases.

As a result, for the period 1991-2017. the overall mortality rate decreased by 20 percent, maternal and infant mortality - by 3.1 times. Life expectancy since 1995 increased by 4.6 years and amounted to 73.7 years. The development of the social life of each country, the formation of the younger generation by spiritually mature, physical healthy individuals depends on the degree of development of the national medical system and access to it by all segments of the population.

The fundamentals of the legislation of the Republic of Uzbekistan on the protection of the health of citizens define health protection as a set of political, economic, legal, social, cultural, scientific, medical, sanitary-hygienic and anti-epidemic measures aimed at preserving and strengthening the physical and mental health of every person, maintaining his long active life, providing him with medical care in case of loss of health. The large-scale reforms carried out in the country's health care system have raised the quality of the medical services provided to a new level, which is important in further strengthening the people's health. The consecutive measures taken are aimed at providing the population with effective drugs, the intensive development of pharmaceuticals. 
Relations in this area are regulated by the current Law on Medicines and Pharmaceutical Activities. In 1997, when this regulatory act was adopted, only two enterprises operated in the republic, which produced about 30 types of drugs. The said law laid the foundation for the development of the pharmaceutical industry in our country, as a result of which today 149 enterprises are operating in the country, producing 1,482 types of drugs. A quality control system has also been created; there are 8 certification bodies for medical products, 15 control and analytical laboratories. Despite this, cardinal changes and reforms taking place in the sphere require updating of some norms of this law.

- National health care systems can be built in three main organizational and economic options:

state (budget);

- Private health care (a system based on voluntary (private) medical insurance or direct payment of medical care);

- Health care system based on social (compulsory) health insurance.

Historically, the state healthcare system was the successor to charitable medicine, in which the church and the state took upon themselves the financing of medical care for the poor. Features of the public health system are as follows:

1. State taxes are the main source of health care financing under such a system, and budgets of various levels are the structures that accumulate health care financial resources;

2. Financing of medical care is carried out mainly according to the structural principle (reimbursement of expenses of the institution as a whole, and not payment of certain medical services);

3. Medical facilities have state non-commercial status;

4. Planning and management of the state system occurs centrally (unitarily);

5. The remuneration of doctors is made by the tariff method, and the rules of hiring and remuneration are dictated by the state;

6. Administrative quality control of medical care.

The main advantages of the state-budget healthcare system:

a high degree of social protection of citizens by estab- lishing guarantees for the provision of free medical care, conducting strict state control over the conditions for the provision of medical care;

High efficiency in influencing the incidence of especially dangerous infectious diseases, as well as in emergency situations.

The 1992 Constitution of the Republic of Uzbekistan enshrined and ensured a number of guarantees for the right of citizens to health protection. This guarantee system also includes a guarantee of qualified medical care. The vast majority of medical resources were the exclusive property of the state, and doctors were state employees.

\section{Analysis}

At the same time, systemic shortcomings and problems that have accumulated in recent years in the organization of health care activities hinder an effective solution to the problems of further improving the system of protecting the health of citizens. Among them:

First, there is no concept and strategic goals in planning and managing the healthcare sector, as a result of which the ongoing reforms are fragmented and do not allow to meet the expectations and demands of the population regarding the quality of healthcare;

Second, the estimated health financing system is based on outdated mechanisms that are not in line with international practice, which leads to inefficient use of financial resources and chronic underfunding of the sector; Third, the low efficiency of work on the prevention and early detection of diseases, patronage and the formation of a healthy lifestyle is the reason for the increase in citizens' requests for specialized medical care;

Fourth, the continuity between the various levels and stages of the provision of medical care to the population, including rehabilitation treatment and rehabilitation, is poorly developed;

The fifth, implemented personnel policy does not allow predicting the prospects for providing specialists at all levels of medical care, especially primary care, as well as the training of organizers and managerial personnel of the health system; 
Citation: Abdurashidovna MF (2019) History of Medicine and Medical Law Journal of Media \& Management.

sixth, poor integration of medical practice with education and science, against the background of the low innovative potential of specialized centers, reflects the unsatisfactory level of introducing advanced achievements of medicine in the diagnostic and treatment process;

seventh, there are no common standards in the field of e-health, modern software products have not been introduced to ensure the integration and effective management of medical services, the existing information systems and technologies are fragmented and narrowly focused.

In order to formulate conceptually new models of organizing and financing healthcare, providing a radical increase in the effectiveness, quality and accessibility of medical care to the population, introducing modern achievements in medical science and technology, and in accordance with the objectives of the Strategy of Action in five priority areas of the development of the Republic of Uzbekistan in 2017-2021, it is considered that the most important areas of reforming the healthcare system of the Republic of Uzbekistan are: improving legislation in the field of healthcare through its unification and adoption of laws of direct action aimed at improving the quality of medical services and protection of the rights of patients, as well as strengthening the responsibility and security of medical workers $[5,6]$.

the formation of a modern management system and a "cluster" model of regional healthcare organization, providing integration best practices of management and quality management of medical services based on international standards, the introduction of an accreditation system for medical and pharmaceutical organizations, licensing of medical and pharmaceutical activities;

improving the system of financing health care, determining the amount of free medical care guaranteed by the state, introducing a system of payment for medical services for a "treated case" by clinic-cost groups and new mechanisms for per capita financing, as well as phased introduction of compulsory medical insurance; improving the efficiency, quality and accessibility of medical care, supporting a healthy lifestyle and preventing diseases, including through the formation of a medical standardization system, the introduction of high-tech diagnostic and treatment methods, effective models of patronage and medical examination; improving the system of maternal and child health based on the development of medical genetics, emergency and specialized medical care for women and children, the introduction of modern screening programs, the creation in the regions of multidisciplinary medical complexes and information systems "Mother and Child"; development of private health care, public-private partnerships and medical tourism, creation of favorable conditions and improvement of a competitive environment for the wide attraction of investments in the healthcare sector;

Further development of the pharmaceutical industry, improvement of pricing mechanisms, expansion of volumes and nomenclature of the production of medicines, medical devices and medical equipment;

the formation of an effective system of training, retraining and advanced training of medical personnel, the development of medical science, including on the basis of certification (accreditation) of medical scientific and educational institutions according to international standards, the introduction of modern educational programs, methods and technologies; widespread introduction of the e-health system, the creation of a set of information systems and databases integrated on the basis of common national standards [7].

The emergence of private health care has historically been associated with satisfying the need for high-quality and expensive medical services for the wealthy segments of the population, and therefore this system cannot be the organizational and financial basis of the national health care systems in general, and should be used as an addition to public health or a system based on social insurance. Even at the beginning of the last century, the opinion was expressed that medical law is a branch of the law, which consists of three parts: social-sanitary, medical-medical legislation and norms that determine the social status of a doctor.

Currently, medical (medical, healthcare) law or the right to protect the health of citizens is an independent complex branch of law, a system of regulatory acts or standards governing organizational, property, personal 
relations, arising in connection with the conduct of sanitary and epidemiological measures and the provision of medical and preventive care to citizens.

Therefore, medical law is formed as a complex branch of legislation, including the norms of many branches of Uzbek law regulating relations in various fields of medical activity - from healthcare management to specific relations between medical institutions and citizens.

Medical activity is closely related to the norms of various branches of law: civil law (regulates property and personal non-property relations);

Labor legislation (regulates social relations related to the labor activity of citizens);

Legislation on marriage and the family (defines the legal basis for family-marriage relations);

Environmental legislation (enforces environmental management standards and environmental safety); administrative law (regulates relations in the process of executive and administrative activities of public authorities and administration);

Criminal law (governs relations to protect citizens from criminal attacks on their rights). When choosing the forms and methods of transformations carried out in public health, the population's need for medical care is taken into account, as well as the economic potential of society to meet these needs. For a long time it was believed that the level of medical care in the country is higher, the greater the cost of developing health care (an extensive path of development).

This situation has largely lost its significance since the beginning of the 1960s, when negative trends in health dynamics were outlined in almost all countries. It became obvious that the extensive way to develop health care has exhausted itself and new approaches and concepts for the development of medical care are required.

Among these new concepts are two areas of development, on the basis of which a modern health care system was built in most developed countries. The first concept (risk factors) suggests that people's health depends not only on health, but also on the way and living conditions with their social and individual-behavioral characteristics, as well as the state of the environment. for promoting health and disease prevention, which in many countries is being implemented in the form of the WHO-recommended Health for All program.

The second concept was related to the need to increase the efficiency of health services, which corresponded to the transition from extensive development of health to intensive. This meant that in many countries of the world they began to measure results with costs, trying to find an optimal model in which relatively small costs would give good results in the form of improved indicators of population health [8].

The legal basis for protecting health in Uzbekistan is primarily the Basic Law of the State - the Constitution of the Republic of Uzbekistan. In Art. 40 of the Constitution states that everyone has the right to protection of health and medical care. The state provides health protection irrespective of gender, race, nationality, language, social origin, official position, place of residence, religion, beliefs, membership of public associations, as well as other circumstances.

Guaranteed protection against any form of discrimination due to the presence of a disease in a citizen.

Citizens have the right to regularly receive reliable and timely information about factors that contribute to maintaining their health or that have a harmful effect on it. Such information is provided by the local administration through the media or directly to citizens upon request. This right of citizens, if necessary, can be established by the courts.

In case of illness, disability, and in other cases, citizens have the right to medical and social assistance, which includes preventive, medical, diagnostic, rehabilitation, prosthetic and orthopedic and dental prosthetics, as well as social measures to care for sick, disabled and disabled people, including payment of temporary disability benefits. Citizens have the right to a medical examination, including an independent one, which is carried out on their personal application in specialized institutions.

Therefore, today the Ministry of Health and Social Welfare of Uzbekistan has become a special authorized body ensuring the constitutional right of citizens

Subsequently, this direction has grown into a strategy 
to qualified medical services and social security, as well as in the field of medical education and science.

The ramified system created in Uzbekistan in essence of extreme service is still considered the standard of emergency and effective medical care in the world. It was on this bridgehead that real battles for the salvation of people unfolded. The chronicle of an independent republic records the opening of emergency medicine centers in each region. Unique in a clear organization, reasonable in structure, expediency and order, but most importantly, as the President conceived, having put forward the idea of its formation, accessible to all. There is still no analogue to it in any country in the world. Yes, there are separate institutes, clinics, but there is such an extensive branch network that makes qualified assistance possible for everyone. Uzbekistan is a policy that finds supporters around the world who are ready to contribute to his good deeds. As a result, loans worth hundreds of millions of dollars, grants, the emergence of joint projects. International foundations, governments of developed countries were imbued with the anxieties of a young republic, seriously perplexed by the health of the nation. And today I would like to note that, in Uzbekistan, 14 million dollars were allocated for lending to the private sector. The funds will be provided in the form of interest-free loans for the development of the private sector. According to the plan, 243 private medical institutions are opening up.

A training center has been created. The center for the development of private medicine in the country and the training of qualified personnel for the field will be opened on the basis of Akfa Medline, a private multidisciplinary medical center. The conditions for the exchange of experience with foreign experts are organized. Specialists from the USA, South Korea, Russia and other countries will be invited to exchange experiences with the opportunity to stay and work in Uzbekistan.New draft health laws are also being adopted. They will address issues of transplantology, public-private partnerships and compulsory health insurance [9].

The scientific novelty of the study is that traditional medicine has always been a popular science, and relics of ancient beliefs in the traditional way of life of the peoples of Uzbekistan appear for the first time in as an object of a special comprehensive historical and medical research. the origin, evolution and local version of traditional medicine as a social phenomenon are investigated. For the first time, a detailed analysis of the evolution of folk treatment, traditions, cults of scientists was carried out. On the basis of a comparative analysis of traditional medicine and traditional treatment of the culture of the Uzbek people, a provision was put forward for the first time on the genesis and continuity of traditional medicine and medical law.

\section{Conclusion}

The synthetic path we have chosen to study such a multifaceted phenomenon as traditional medicine in Islam, using the socio-cultural example systems of encyclopedic scientists like Ibn Sina and other scientists have proven effective at the present stage. In modern realities, the problems of medicine are gaining priority. In this regard, it seems very useful to study the ancient traditions of the Uzbek people, aimed at traditional medicine, as well as to bring the results of these studies to the general public. Therefore, today, lawyers must be trained and possess knowledge of medical law with modern legislation, including the main by-laws in the field of medicine;

1. to acquaint students with the formation and development trends of medical law in Russia and the fundamentals of international law in the field of medicine;

2. Stress the importance of medical ethics and the problems of bioethics as the basis for creating legal norms in medicine in the provision of medical care;

3. To give an idea of the system, structure, principles and objectives of healthcare in Uzbekistan;

4. analysis of the main provisions of medical law and features of application for various problems, and situations, as well as the rights of the patient, the rights, duties, behavior and responsibilities of the health worker;

5. To teach lawyers to navigate in a specific situation arising in professional activities, and make the right decision on the basis of medical law. The article is relevant and important for:

6. Lawyers of medical organizations;

7. Heads and deputy heads of medical organizations;

8. Managing medical centers (clinics);

9. Chief doctors; 
Citation: Abdurashidovna MF (2019) History of Medicine and Medical Law Journal of Media \& Management. SRC/JMM-101. DOI: doi.org/10.47363/JMM/2019(1)101

\section{References}

1. Constitution of the Republic of Uzbekistan (2018)

T.Uzbekistan S 40.

2. Kemper M (2017) Stutying Islam in the Soviet Union // Amsterdam: Vossiuspers UvA. URL: http://www.oratiereeks.nl/upload/pdf/PDF8952oratie_Kemper.PDF.

3. Olcott MB (2016) Essay on the history of Islam in Uzbekistan // Carnegie Moscow Center. URL: http:// carnegieendowment.org/files//WhilwindofJihadChapter1.pdf.

4. Kehl-Bodrogi K (2008) Religion is Not So Strong Here: Muslim Religious in Khorezm After Socializm Lit.

5. Allworth E (1990) The modern Uzbeks: from the fourteenth century to the present: a cultural history Stanford.

6. Bennett GG, AL Dolgopolsky M (2006) Teachers of Wisdom / trans. from English.

7. Baltaev Abu Ali Ibn Sino (1980) the Great Conqueror, Scientific Encyclopedist of the Middle East from the "Fan" Tashkent.

8. ZM Babur (1957-1996) "Baburnome" from "Fan" Tashkent, and Temur "Laying Temur" Tashkent.

9. NM Makhmudova (1969) "History of the development of internal medicine in Uzbekistan" from the "Fan" Tashkent. 